\title{
Influence of Coarse Aggregate Type on the Mechanical Strengths and Durability of Cement Concrete
}

\author{
Lin Wang ${ }^{1}$, Han Yong ${ }^{1}$, Jinyu Lu ${ }^{1}$, Chunxue Shu ${ }^{1}$ and Hui Wang ${ }^{2,3, *}$ \\ 1 School of Civil and Transportation Engineering, Beijing University of Civil Engineering and Architecture, \\ Beijing 100044, China; wanglin1@bucea.edu.cn (L.W.); 13370177826@163.com (H.Y.); \\ lujingyu4618@163.com (J.L.); shuchunxue1@126.com (C.S.) \\ 2 School of Civil and Environmental Engineering, Ningbo University, Ningbo 315000, China \\ 3 State Key Laboratory of Materials-Oriented Chemical Engineering, Nanjing 210000, China \\ * Correspondence: huiwang123@aliyun.com
}

check for updates

Citation: Wang, L.; Yong, H.; Lu, J.; Shu, C.; Wang, H. Influence of Coarse Aggregate Type on the Mechanical Strengths and Durability of Cement Concrete. Coatings 2021, 11, 1036. https://doi.org/10.3390/ coatings11091036

Academic Editor: Valeria Vignali

Received: 1 August 2021

Accepted: 25 August 2021

Published: 28 August 2021

Publisher's Note: MDPI stays neutral with regard to jurisdictional claims in published maps and institutional affiliations.

Copyright: (c) 2021 by the authors. Licensee MDPI, Basel, Switzerland. This article is an open access article distributed under the terms and conditions of the Creative Commons Attribution (CC BY) license (https:// creativecommons.org/licenses/by/ $4.0 /)$.

\begin{abstract}
In this paper, the influence of coarse aggregate on the slump flow and the following mechanical strengths (flexural and compressive strengths), the shrinkage rate, the chloride penetration resistance, and the freeze-thaw resistance were investigated. Water-binder ratios in this study were $0.22,0.30,0.34$, and 0.45 . Sand ratio in this study was 0.45 . All samples were cured for $7 \mathrm{~d}, 14 \mathrm{~d}$, $28 \mathrm{~d}$, and $56 \mathrm{~d}$, respectively. Results indicated that the fluidity of cement concrete with different coarse aggregate increased in this order: gneiss $<$ limestone $<$ basalt $<$ diabase. The mechanical strengths and shrinkage rate increased obviously with the increasing curing age when the curing age ranged from 7 days to 28 days. However, the mechanical strengths and shrinkage rate trended to a stable value when the increasing curing age increased from 28 days to 56 days. The mechanical strengths with different coarse aggregate increased in this order: diabase $<$ basalt $<$ limestone $<$ gneiss. Meanwhile, the shrinkage rate demonstrated this trend of development: diabase $<$ basalt $<$ limestone $<$ gneiss. The resistance to freeze-thaw cycles of cement concrete decreased with the increasing water-binder ratio. Meanwhile, the resistance to freeze-thaw cycles was closely related to the types of coarse aggregate.
\end{abstract}

Keywords: coarse aggregate; mechanical strengths; shrinkage rate; chloride penetration; freezethaw resistance

\section{Introduction}

Cement concrete with large fluidity has been widely applied in recent construction industry of the whole world [1]. The ultra-high performance concrete has been applied in the production and application of bridge deck [2-4]. The workability and mechanical properties have been researched widely [5].

Coarse aggregate is the main composition of the cement concrete [6]. Some researchers have paid attention to the research of mechanical performances and durability of normal concrete with different coarse aggregate [7-10]. As some researchers [11-13] pointed out, the mechanical strength of coarse aggregate was the main factor affecting the mechanical performance of cement concrete when the other components of large fluidity cement concrete are the same. Moreover, the mechanical strength of coarse aggregate had a significant influence on the durability of large fluidity cement concrete [14-16]. However, coarse aggregate with higher strength could lead to a larger difference between the deformation and cement paste, thus increasing the micro cracks in the interface transition zone. Therefore, the mechanical strength and durability of large fluidity cement concrete were reduced.

Coarse aggregate mainly plays the role of skeleton in cement concrete [17-20]. Results of some research show that the physical and chemical properties of coarse aggregate demonstrated key roles on the mechanical strength, the fluidity, the setting time, and durability of cement concrete. When the external force is exerted on the cement concrete, 
micro cracks formed and increased due to the different elastic moduli between coarse aggregate and cement matrix, thus weakening the mechanical strength and durability of cement concrete. In addition to the function of skeleton and filling, coarse aggregate also plays a role in inhibiting the shrinkage of concrete [21-23]. Hearn et al. [24] concluded that the dry shrinkage of concrete is less than that of mortar due to "inhibition effect" of coarse aggregate on dry shrinkage, when the cement mortar matrix of cement concrete and cement mortar are the same.

Several researchers [25] pointed out that the mechanical strength of coarse aggregate demonstrated a positive correlation on the mechanical strength and the durability of cement concrete. However, higher mechanical strength of coarse aggregate may induce the reduction of mechanical strength of cement concrete with high fluidity due to the decreased water absorption of coarse aggregate [26]. Few researchers paid attention to the performance of coarse aggregate on the mechanical strength of cement concrete with high fluidity.

When the cement concrete is used in the environment, the penetration of chloride ions and the freeze-thaw cycles demonstrate significant influence on the corrosion resistance and long-term mechanical properties. However, little attention has been paid to the influence of coarse aggregate on the durability of high fluidity cement concrete.

In this paper, the diabase, basalt, limestone and gneiss on the mechanical strengths (flexural and compressive strengths), the shrinkage rate, the chloride penetration resistance, and the freeze-thaw resistance are investigated. Water-binder ratios in this study are $0.22 \sim 0.45$ and the curing ages are 7 56 d. This study will provide a reference for the reasonable use of coarse aggregate in the engineering construction industry.

\section{Experimental Section}

\subsection{Raw Materials}

In this research, the ordinary Portland cement with the strength grade of $42.5 \mathrm{MPa}$, the appearance density of $3.0 \mathrm{~g} / \mathrm{cm}^{3}$, the initial time of $151 \mathrm{~min}$, and the final setting time of 234 min respectively produced by Beijing Jinyu Conch Co., Ltd., Beijing, China, were used. Grade I fly ash (FA) provided by Beijing Jingyeda New Building materials Co., Ltd., Beijing, China, S95 ground granulated blast furnace slag (GGBS) produced by Chengdu Yuefang Science and Trade Co., Ltd., Chengdu, China and the silica fume provided by Henan Yixiang New Material Co., Ltd., Zhengzhou, China, were used as mineral admixtures. The density, the specific surface area, and the loss on ignition of GGBS used in this study are $2.9 \mathrm{~g} / \mathrm{cm}^{3}, 436 \mathrm{~m}^{2} / \mathrm{g}$, and $2.3 \%$, respectively. The specific surface area of silica fume (SF) is $15 \mathrm{~m}^{2} / \mathrm{g}$; meanwhile, the SF consists of $95.5 \% \mathrm{SiO}_{2}$ and the density of $\mathrm{SF}$ is $2.2 \mathrm{~g} / \mathrm{cm}^{3}$. The performance index of cement, SF, and GGBS meets the requirements of GB175-2007, GB/T21236-2007, and GB/T-18046-2008, respectively. Natural river sand with a fineness modulus of 2.40 produced by Beijing Yugou Group Co., Ltd, Beijing, China. is used as fine aggregate. Polycarboxylate water-reducing agent with a water reduction rate of $25 \%$ and solid content of $15 \%$ produced by Hebei Hezhong Building Materials Co., Ltd, Langfang, China. is used to adjust the fluidity of concrete. Gneiss, limestone, basalt, and diabase with a density of $2.58,2.60,2.74$, and $2.65 \mathrm{~g} / \mathrm{cm}^{3}$ are used as coarse aggregate, respectively. The particle size of the coarse aggregate is $5-31.5 \mathrm{~mm}$. The crushing indexes of gneiss, limestone, basalt, and diabase are $10 \%, 6 \%, 5 \%$, and $3 \%$. The chemical composition and content of fly ash and slag powder are shown in Table 1.

Table 1. Chemical composition and content of fly ash and slag powder (\%).

\begin{tabular}{ccccccccc}
\hline Types & $\mathbf{A l}_{\mathbf{2}} \mathbf{O}_{\mathbf{3}}$ & $\mathbf{S i O}_{\mathbf{2}}$ & $\mathbf{F e}_{\mathbf{2}} \mathbf{O}_{\mathbf{3}}$ & $\mathbf{C a O}$ & $\mathbf{S O}_{\mathbf{3}}$ & $\mathbf{K}_{\mathbf{2}} \mathbf{O}$ & $\mathbf{M g O}$ & Other \\
\hline Cement & 5.47 & 20.86 & 3.94 & 62.23 & 2.66 & 0.48 & 1.73 & $/$ \\
Fly ash & 42.86 & 36.75 & 8.65 & 5.23 & 0.49 & 0.43 & 0.24 & 5.35 \\
GGBS & 14.86 & 26.75 & 0.89 & 49.42 & 2.49 & 0.46 & 3.24 & 1.89 \\
$\begin{array}{l}\text { Silica } \\
\text { fume }\end{array}$ & 0.27 & 94.5 & 0.83 & 0.54 & $/$ & $/$ & 0.97 & 1.9 \\
\hline
\end{tabular}




\subsection{Samples Preparation and Measurement}

The water absorption of coarse aggregate is tested according to the following process: the coarse aggregate is immersed in distilled water for more than $48 \mathrm{~h}$ until the mass remains unchanged. Then, the coarse aggregate is removed from the water and wiped off by wet rags. After that, the mass $\left(m_{0}\right)$ of coarse aggregate is weighed. After this process, the mass $(m)$ of coarse aggregate is weighed after being dried out.

The water absorption rate $(W)$ can be calculated by Equation (1):

$$
W=\frac{m-m_{0}}{m_{0}}
$$

The compressive strength of parent rock of coarse aggregate is conducted as the following steps:

The parent rock of coarse aggregate is core sampling by a drill core sampler with the drill bit diameter of $50 \mathrm{~mm}$, and then all core samplers are cut into cylinders with $50 \mathrm{~mm}$. All cylinders are applied in the measurement of compressive strength. The experiments of water absorption rate of coarse aggregate and the compressive strength of cylinders are carried out according to the GB/T 14685-2011 Chinese standard [27].

In order to prepare the cement concrete specimens, the preparation can be described as follows.

The binder materials (cement, FA, GGBS and SF) sand and coarse aggregate are firstly added in the concrete mixer and stirred at a low speed of $60 \mathrm{rpm}$ for $1 \mathrm{~min}$. After this mixing, water and water-reducing agent are mixed in a glass for 2 min and added to the concrete mixer and mixed for the last $3 \mathrm{~min}$. Finally, all fresh mixture is poured into oiled molds to form specimens with sizes of $100 \mathrm{~mm} \times 100 \mathrm{~mm} \times 100 \mathrm{~mm}, 100 \mathrm{~mm} \times$ $100 \mathrm{~mm} \times 300 \mathrm{~mm}, 100 \mathrm{~mm} \times 100 \mathrm{~mm} \times 400 \mathrm{~mm}$ and $\Phi 100 \mathrm{~mm} \times 400 \mathrm{~mm}$. All specimens are sealed by plastic sheets for 2 days curing at room temperature $\left(20 \pm 2{ }^{\circ} \mathrm{C}\right)$ and then demolded. After demolding, the specimens are cured in a standard maintenance environment $\left(20 \pm 2{ }^{\circ} \mathrm{C}\right.$, above $90 \%$ relative humidity). When 28 days standard curing are finished, specimens with sizes of $100 \mathrm{~mm} \times 100 \mathrm{~mm} \times 100 \mathrm{~mm}$ and $100 \mathrm{~mm} \times 100 \mathrm{~mm}$ $\times 400 \mathrm{~mm}$ are applied in the measurement of compressive and flexural strengths, respectively. The shrinkage rate is determined by fixing the dial indicator on the longitudinal axis of the concrete specimens with a size of $100 \mathrm{~mm} \times 100 \mathrm{~mm} \times 300 \mathrm{~mm}$ as shown in Figure 1. The shrinkage rate is obtained by calculating the reduction rate of values from the dial indicator. All mechanical property parameters are determined according to the GB/T 50081-2002 Chinese standard [28]. Specimens with a size of $100 \mathrm{~mm} \times 100 \mathrm{~mm} \times$ $400 \mathrm{~mm}$ are immersed in the distilled water until saturated. Then, the saturated specimens are moved to the rapid freezing and thawing test machine for concrete to carry out the fast freeze-thaw experiment. Distilled water is used as freeze-thaw medium. Specimens with a size of $\Phi 100 \mathrm{~mm} \times 50 \mathrm{~mm}$ are immersed in the BSJ concrete intelligent vacuum water filling machine produced by Shanghai Meiyu Instrument Equipment Co., Ltd. (Shanghai, China). After water saturation, an ion penetration experiment is conducted. The freezethaw experiment and ion penetration experiment are carried out according to Chinese standard GB/T 50082-2009 [29]. 


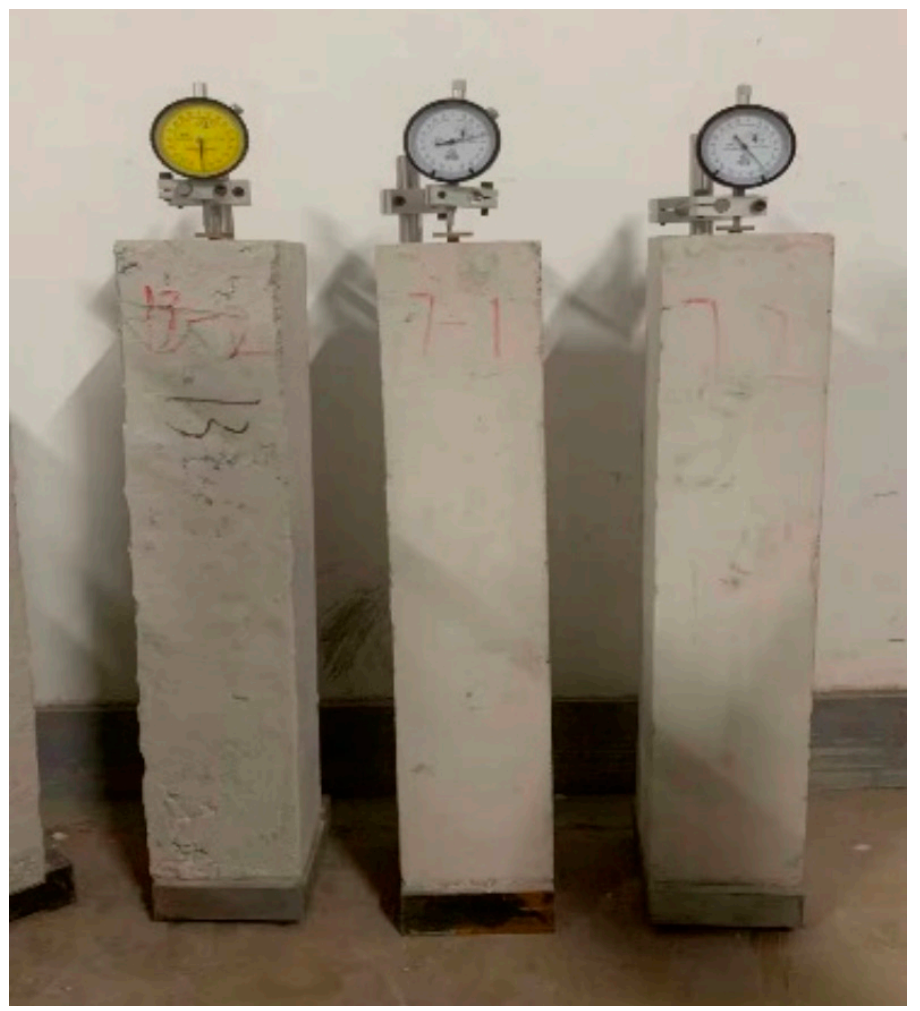

Figure 1. Measurement of the expansion rate of specimen.

\section{Results and Discussion}

\subsection{Properties of Coarse Aggregate}

Figure 2 shows the water absorption of coarse aggregate, and Figure 3 shows the compressive strength of rock of coarse aggregate. As shown in Figures 2 and 3, the water absorption of coarse aggregate decreases in this order: gneiss $>$ limestone $>$ basalt $>$ diabase and the compressive strength of rock of coarse aggregate increases in this order: gneiss < limestone $<$ basalt $<$ diabase, indicating that lower mechanical strength of coarse aggregate results in higher water absorption.

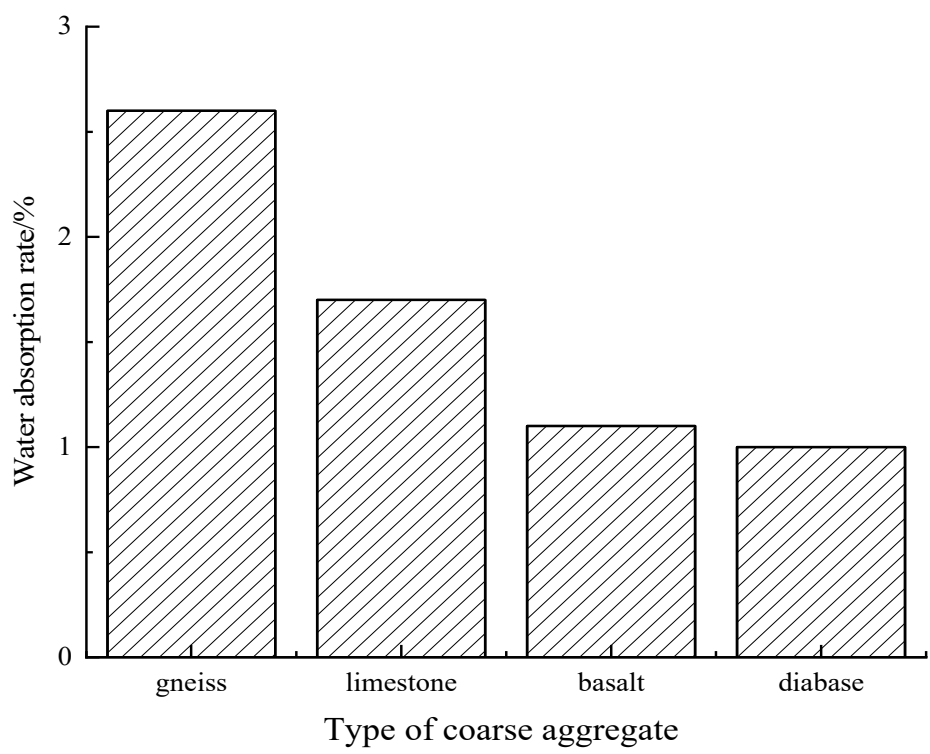

Figure 2. Water absorption of a coarse aggregate. 


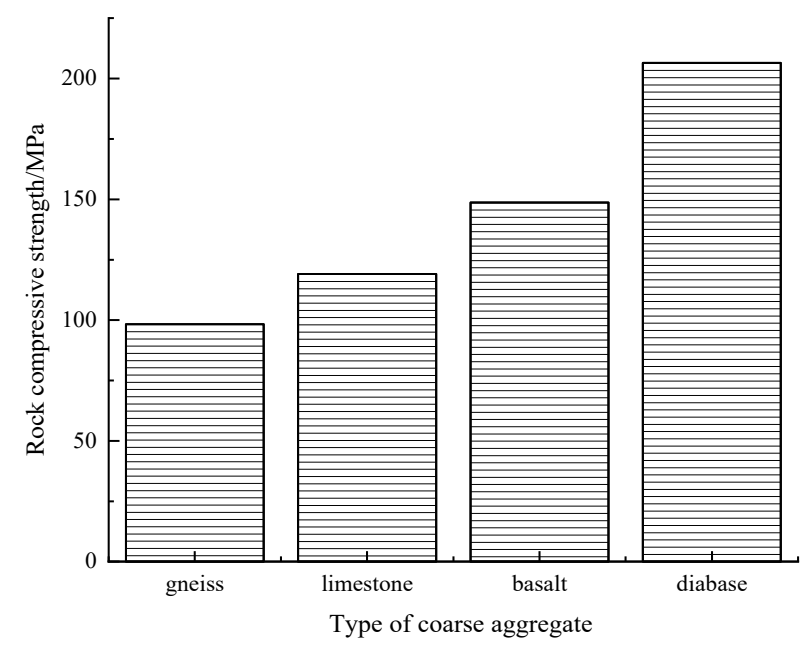

Figure 3. Compressive strength of the rock of a coarse aggregate.

\subsection{The Rheological Properties of Fresh Paste}

Figure 4 shows the dosage of water-reducing agent for cement concrete with different types and the same content of coarse aggregate. In this study, the slump flow of all fresh paste is kept to $500-510 \mathrm{~mm}$. The dosage of a water-reducing agent is applied to reflect the fluidity of fresh cement concrete. Higher dosage of a water-reducing agent means lower fluidity. Therefore, it can be obtained from Figure 4 that the dosage of a waterreducing agent decreases in this order: fresh concrete-gneiss $>$ fresh concrete-limestone $>$ fresh concrete-basalt $>$ fresh concrete-diabase, indicating that the fluidity of fresh concrete demonstrates this order: fresh concrete-gneiss $<$ fresh concrete-limestone $<$ fresh concretebasalt $<$ fresh concrete-diabase. The variation of the rheological performance induced by the coarse aggregate is attributed to the fact that the water absorption capacity of coarse aggregate demonstrates in this order: diabase $>$ basalt $>$ limestone $>$ gneiss, thus resulting in the results of the fluidity. It can be observed from Figure 4 that the dosage of waterreducing agent increases with the decreasing water-binder ratio. This is attributed to the fact that cement concrete with a lower water-binder ratio possesses less water, thus needing more water-reducing agent [30].

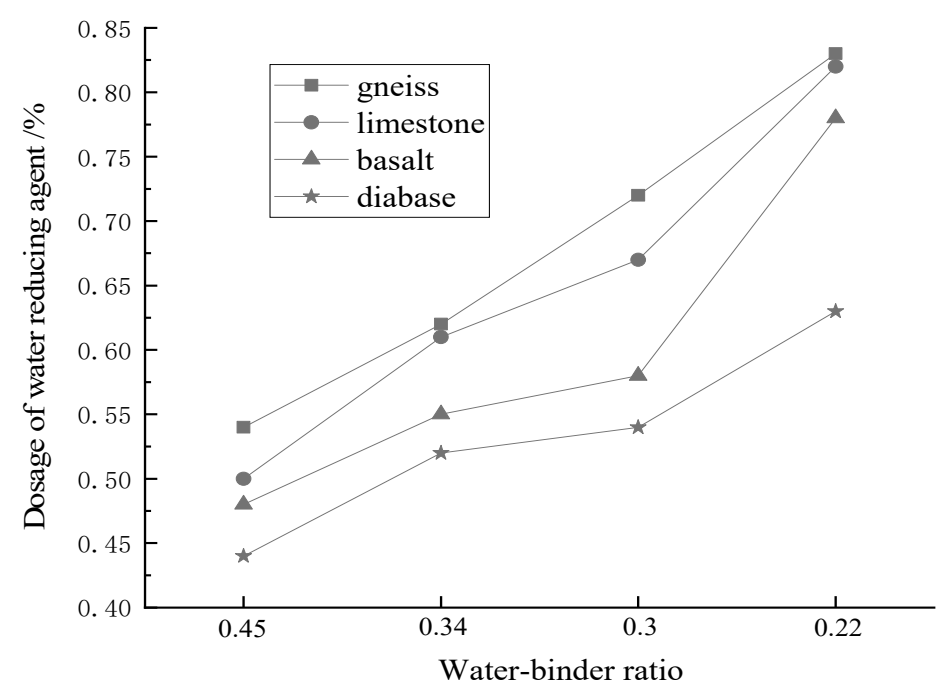

Figure 4. The dosage of a water-reducing agent for cement concrete.

Figures 5 and 6 show the mechanical strengths (compressive and flexural strengths) of cement concrete with coarse aggregates of gneiss, limestone, basalt, and diabase, respectively. As shown in Figures 5 and 6, the mechanical strengths of cement concrete increase 
with the increasing curing age. When the water-binder ratio is higher than 0.34 , the mechanical strengths demonstrate in this order: Specimens-limestone $>$ Specimens-gneiss $>$ Specimens-diabase $>$ Specimens-basalt. However, when the water-binder ratio is lower than or equal to 0.3 , the compressive strength decreases in this order: Specimens-diabase > Specimens-basalt $>$ Specimens-limestone $>$ Specimens-gneiss. The reasons for the results of mechanical strengths can be explained as follows:

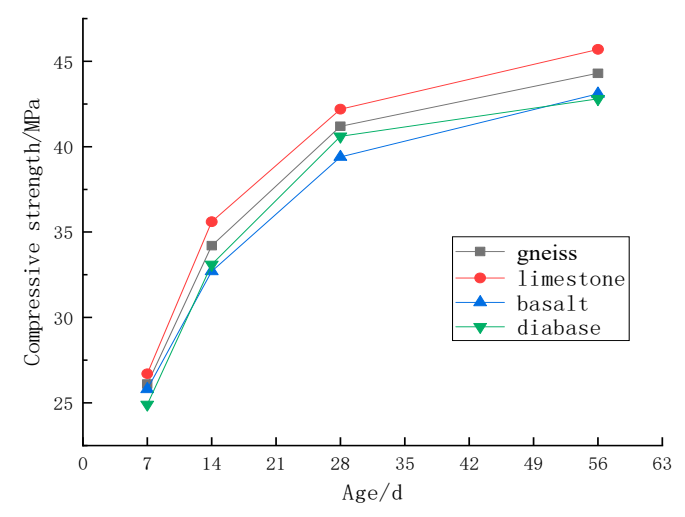

(a) $\mathrm{w} / \mathrm{b}-0.45$

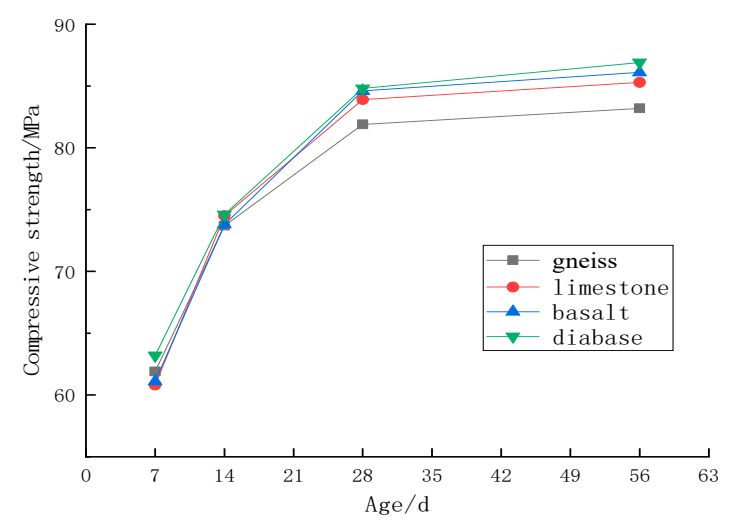

(c) $\mathrm{w} / \mathrm{b}-0.30$

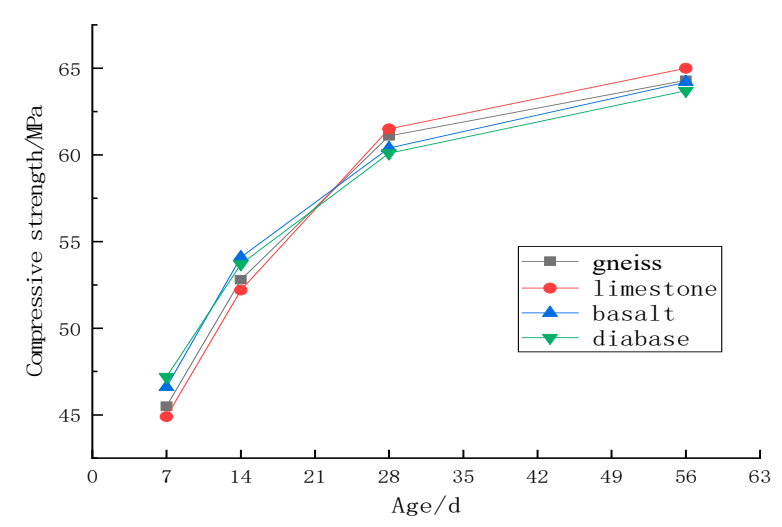

(b) $\mathrm{w} / \mathrm{b}-0.34$

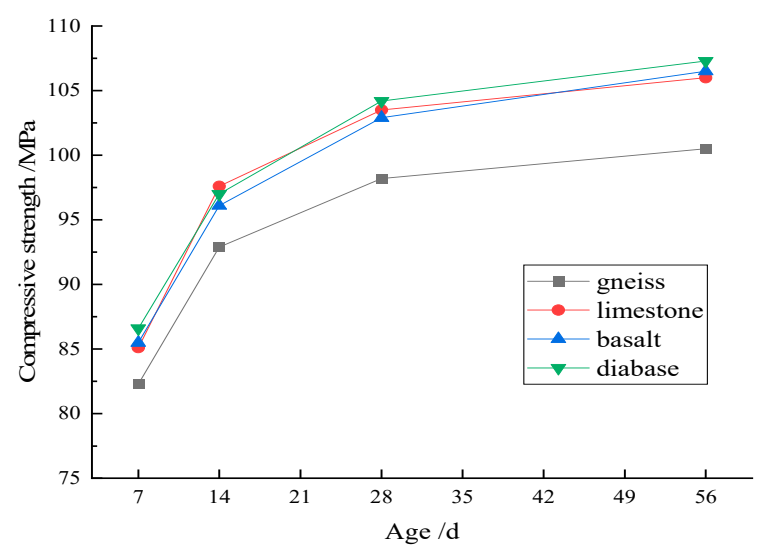

(d) $\mathrm{w} / \mathrm{b}-0.22$

Figure 5. The compressive strength of concrete with different types of coarse aggregate: (a) water-binder ratio of 0.45 ; (b) water-binder ratio of 0.34 ; (c) water-binder ratio of 0.30 and (d) water-binder ratio of 0.22 .

When the water-binder ratio is lower than or equal to 0.3 , the mechanical strengths are dominated by the water-binder ratio of cement concrete and the mechanical strengths of coarse aggregate [31-33]. However, the water absorption capacity of coarse aggregate shows in this order: diabase $>$ basalt $>$ limestone $>$ gneiss. When the strength of coarse aggregate is the main factor, cement concrete with higher strength coarse aggregate presents higher mechanical strength. However, when water-binder ratio of cement concrete is the main factor, cement concrete has a higher water absorption coarse aggregate, which can lead to decreasing the water-binder ratio of cement concrete possessing higher mechanical strength. Therefore, when the water-binder ratio is higher than 0.34, the compressive strength of cement concrete with coarse aggregates of limestone is the highest and the compressive strength of cement concrete with coarse aggregates of basalt is the lowest. Meanwhile, when the water-binder ratio is lower than or equal to 0.3 , the mechanical strengths decrease in this order: Specimens-diabase $>$ Specimens-basalt $>$ Specimenslimestone $>$ Specimens-gneiss. 


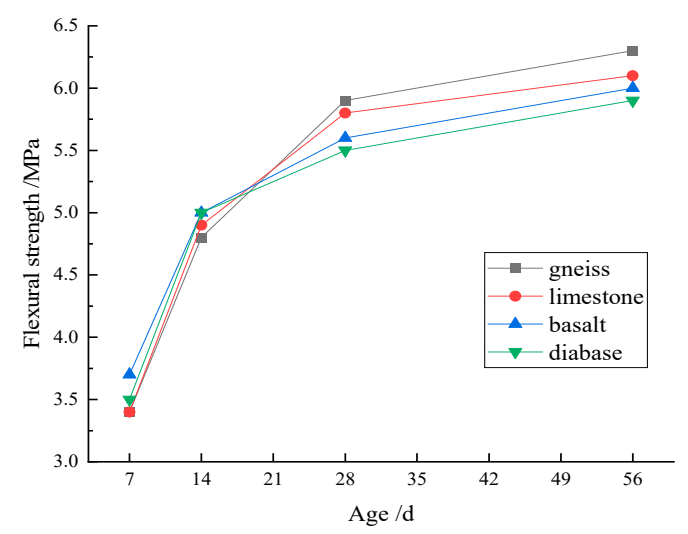

(a) $\mathrm{w} / \mathrm{b}-0.45$

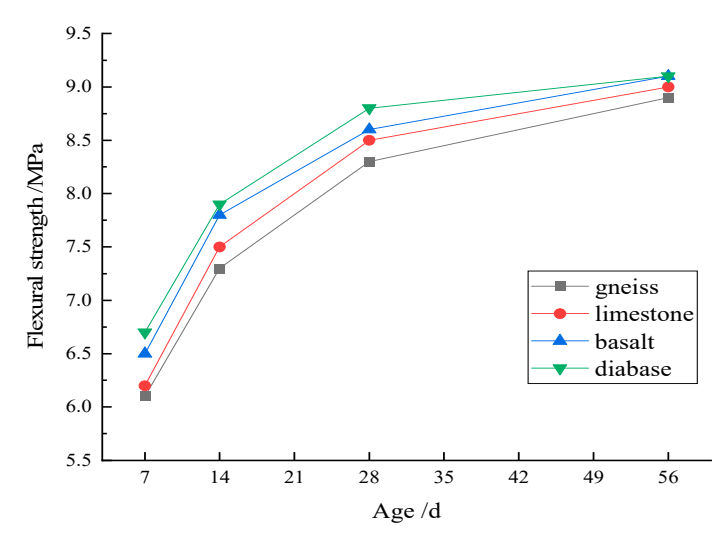

(c) $w / b-0.3$

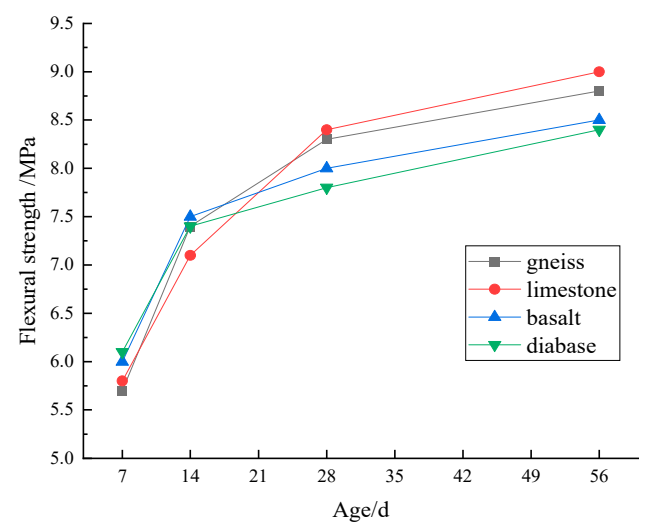

(b) $\mathrm{w} / \mathrm{b}-0.34$

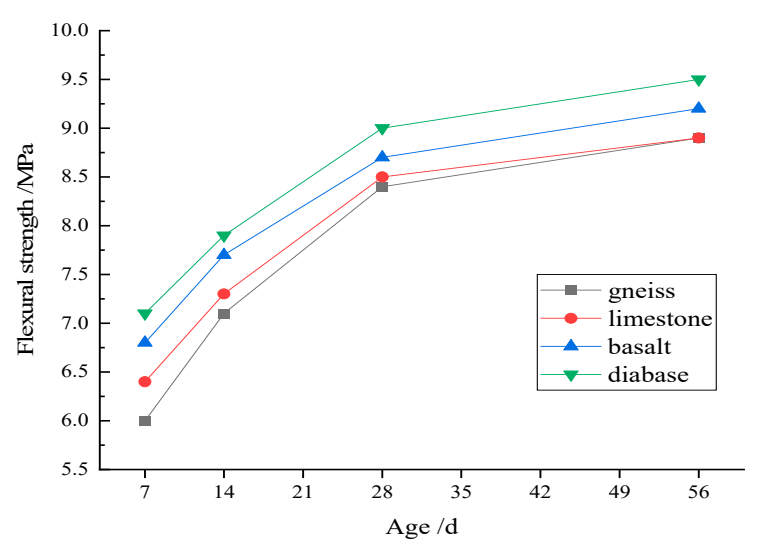

(d) $\mathrm{w} / \mathrm{b}-0.22$

Figure 6. The flexural strength of concrete with different types of coarse aggregate: (a) water-binder ratio of 0.45 ; (b) waterbinder ratio of $0.34 ;(\mathbf{c})$ water-binder ratio of 0.30 and (d) water-binder ratio of 0.22 .

Figure 7 shows the shrinkage rate of cement concrete with different types of coarse aggregate. As shown in Figure 7, the shrinkage rate of cement concrete firstly increases and then keeps a stable increasing trend with the increasing curing age. It can be observed from Figure 7 that the shrinkage rate of concrete with different types of coarse aggregate decreases in this order: Specimens-diabase $>$ Specimens-basalt $>$ Specimensgneiss $>$ Specimens-limestone. Finally, compared Figure $7(\mathrm{a}-\mathrm{d})$, it can be obtained that the decreasing water-binder ratio is able to increase the shrinkage rate of cement concrete.

Figure 8 shows the electrical flux of cement concrete determined by the measurement of chloride ion permeability by electric flux method according to Chinese standard GB/T 50082-2009. It can be depicted from Figure 8 that the decreasing water-binder ratios lead to the reduction of electrical flux. This is attributed to the fact that the decreasing water-binder ratio can improve the compactness of cement concrete, thus decreasing the permeability of chloride ion and reducing the electrical flux $[34,35]$. Moreover, the electrical flux of cement concrete with different types of coarse aggregate decrease in this order: Specimensgneiss $>$ Specimens-limestone $>$ Specimens-basalt $>$ Specimens- diabase. The results of the electrical flux of cement concrete can be attributed to the fact that the chloride permeability of cement concrete is dependent on its compactness. When the mechanical strength of coarse aggregate is high and the following compactness is high, the electrical flux of cement concrete increases with the decreasing mechanical strength of coarse aggregate. 


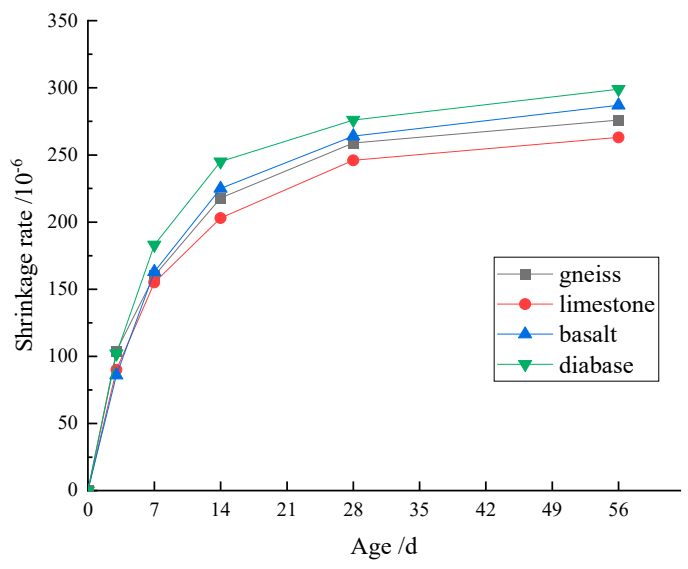

(a) $\mathrm{w} / \mathrm{b}-0.45$

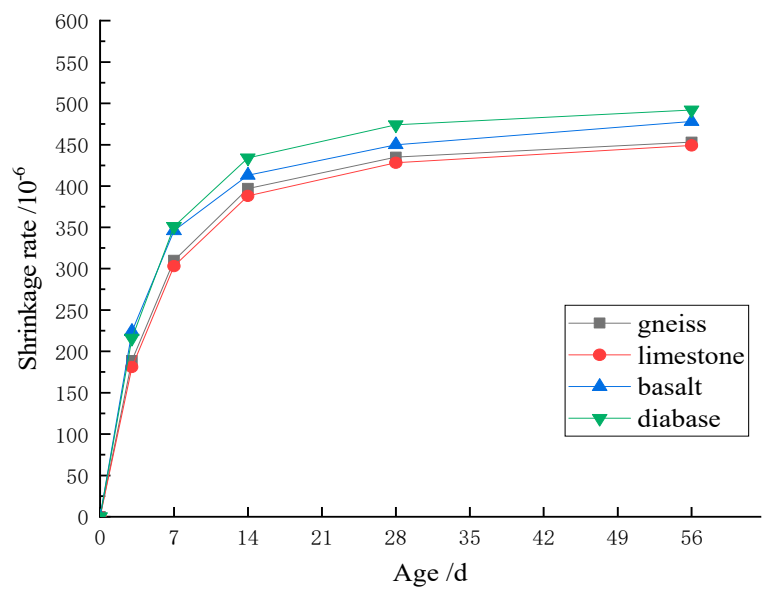

(c) $\mathrm{w} / \mathrm{b}-0.3$

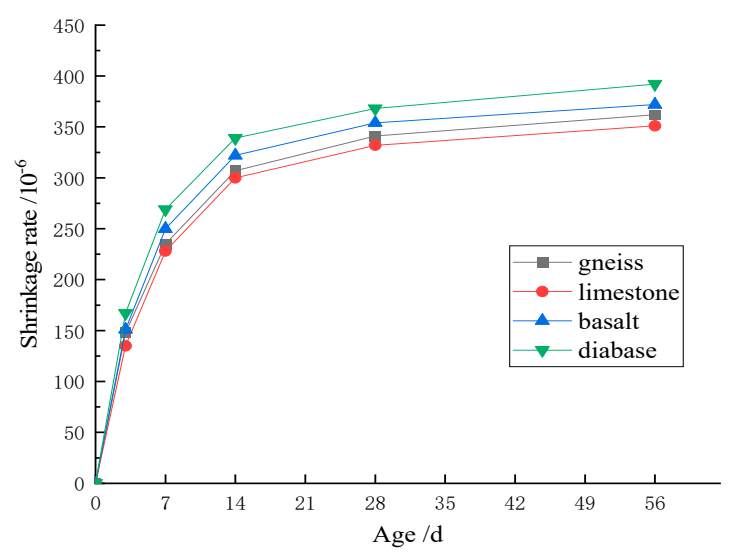

(b) $w / b-0.34$

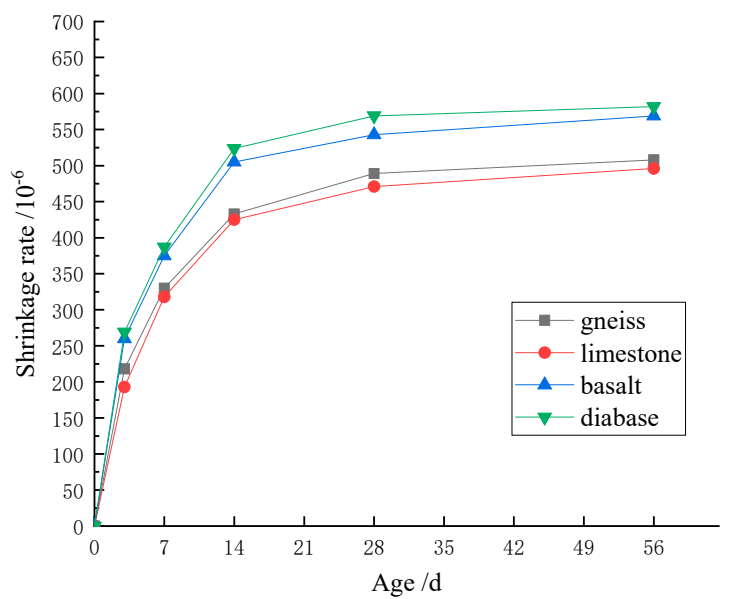

(d) $\mathrm{w} / \mathrm{b}-0.22$

Figure 7. The shrinkage rate of coarse aggregate concrete: (a) water-binder ratio of 0.45; (b) water-binder ratio of 0.34 ; (c) water-binder ratio of 0.30 and (d) water-binder ratio of 0.22 .

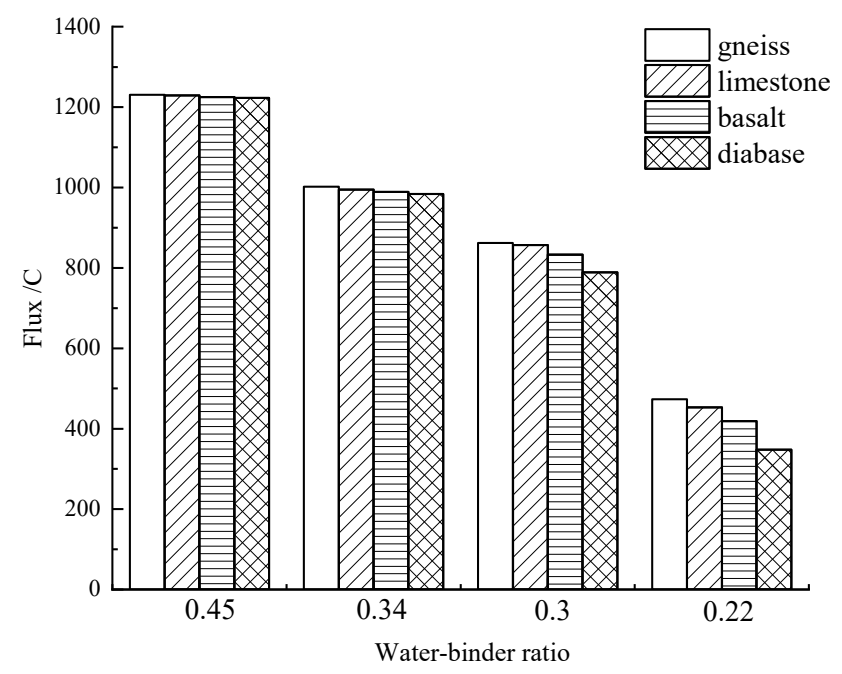

Figure 8. The electrical flux of cement concrete.

Figure 9 shows the mass loss ratio of cement concrete with different types of coarse aggregate. It can be observed from Figure 9 that the mass loss ratio increases with the increasing freeze-thaw cycles. Moreover, the decreasing water-binder ratio leads to the reduction of mass loss ratio. The variation of the mass loss ratio can be attributed to 
the fact that the decreasing water-binder ratio can increase the compactness of cement concrete, thus reducing the pore water in concrete and reducing the frost heaving stress during freeze-thaw cycles. Therefore, the mass loss ratio decreases with the decreasing water-binder ratio.

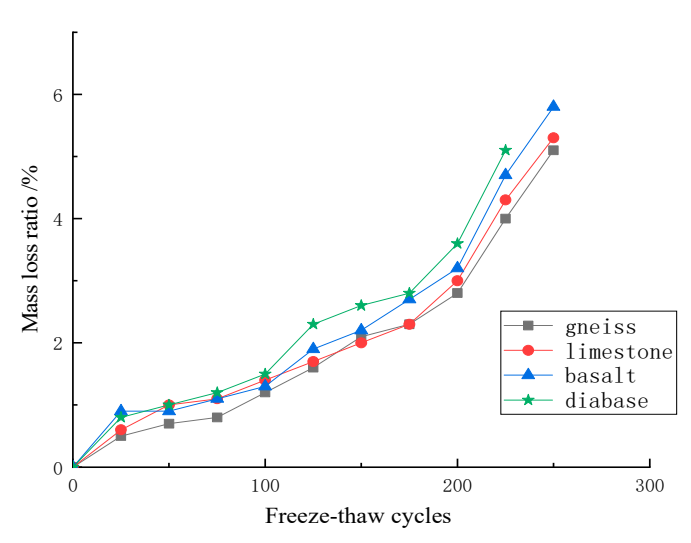

(a) $\mathrm{w} / \mathrm{b}-0.45$

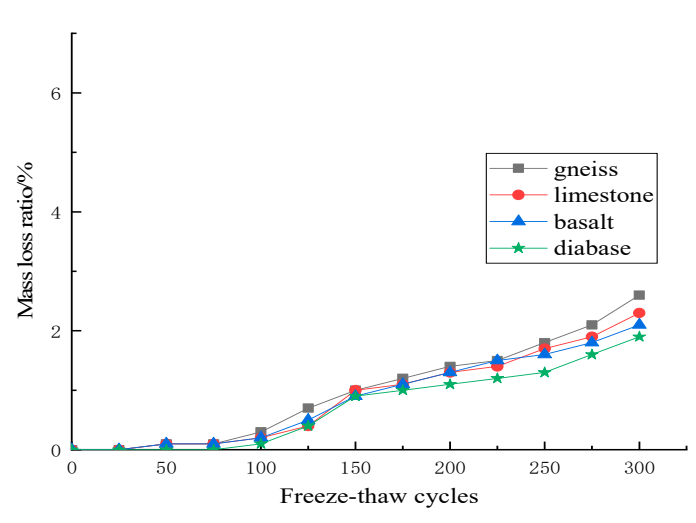

(c) $w / b-0.3$

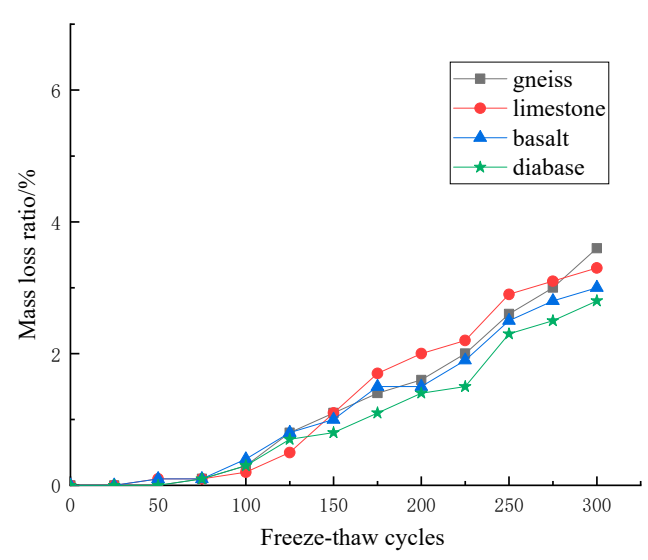

(b) $\mathrm{w} / \mathrm{b}-0.34$

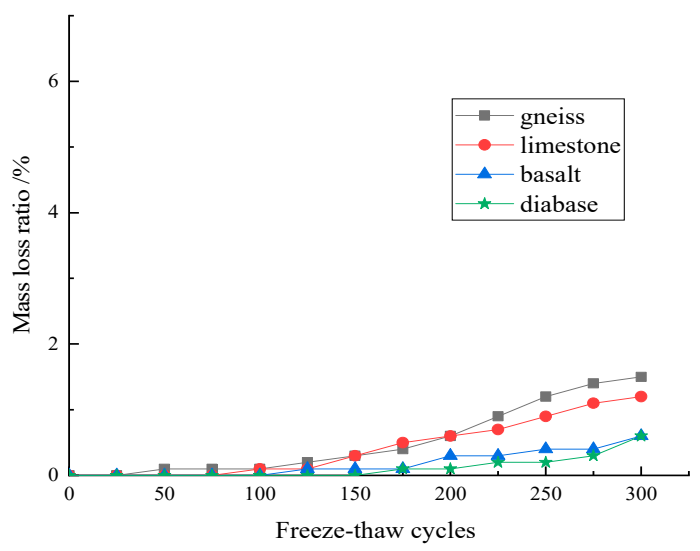

(d) w/b-0.22

Figure 9. The mass loss ratio during freeze-thaw cycles: (a) water-binder ratio of 0.45 ; (b) water-binder ratio of 0.34 ; (c) water-binder ratio of 0.30 and (d) water-binder ratio of 0.22 .

Figure 10 shows the relative dynamic modulus during freeze-thaw cycles. As depicted in Figure 10, the relative dynamic modulus decreases with the increasing times of freezethaw cycles. This is attributed to the fact that the inner micro cracks of the cement concrete are extended and expanded by the frozen-heave stress from freeze-thaw cycles. The increased inner micro cracks can reduce the velocity of the acoustic wave leading eventually to decreasing the relative dynamic modulus of cement concrete [36-39]. Moreover, as observed from Figure 10, the relative dynamic modulus of cement concrete with a lower water-binder ratio after different freeze-thaw cycles is higher than that with a higher water-binder ratio. The variation of the relative dynamic modulus during freeze-thaw cycles can be attributed to the fact that the internal structure of cement concrete with a lower water-binder ratio is more compact than that of cement concrete with a higher waterbinder ratio [40-43]. Therefore, the relative dynamic modulus increases with the increasing water-binder ratio. When the water-binder ratio of cement concrete is 0.45 , the relative dynamic modulus decreases in this order: Specimens-gneiss $>$ Specimens-limestone $>$ Specimens-basalt $>$ Specimens-diabase. Meanwhile, when the water-binder ratios are 0.34, 0.3 , and 0.22 , the relative dynamic modulus decreases in this order: Specimens-diabase $>$ Specimens-gneiss $>$ Specimens-basalt $>$ Specimens- limestone. 


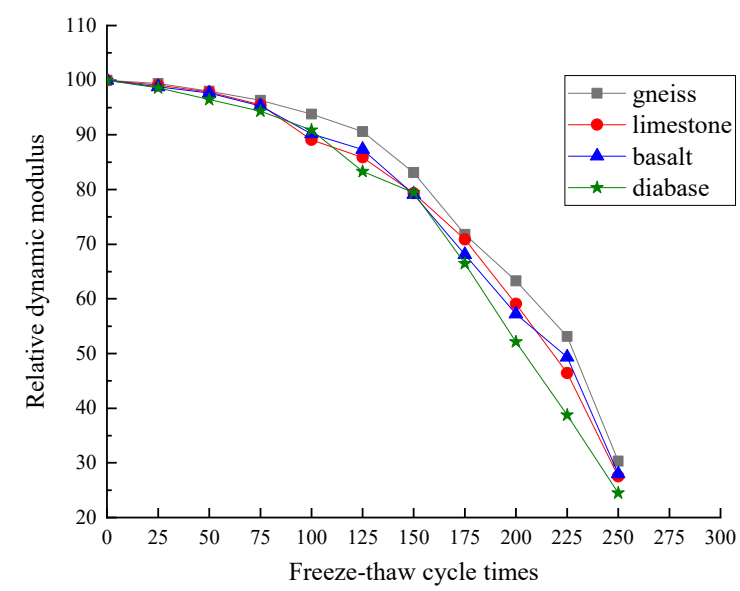

(a) w/b-0.45

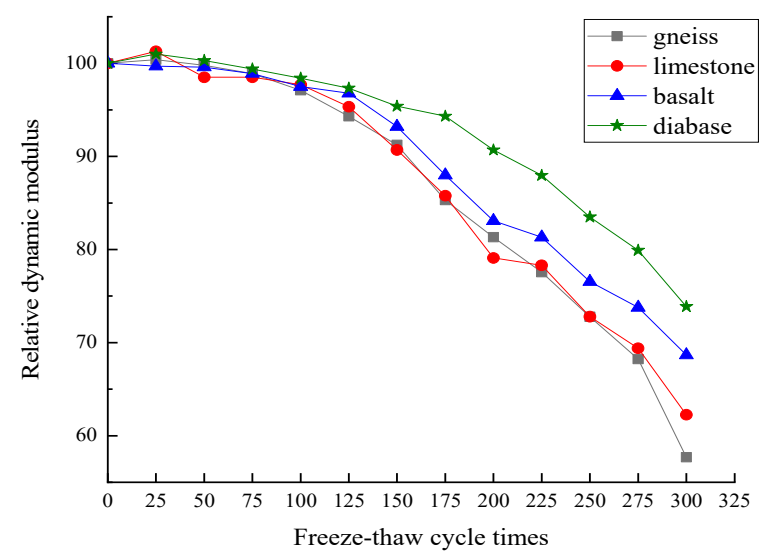

(c) $w / b-0.3$

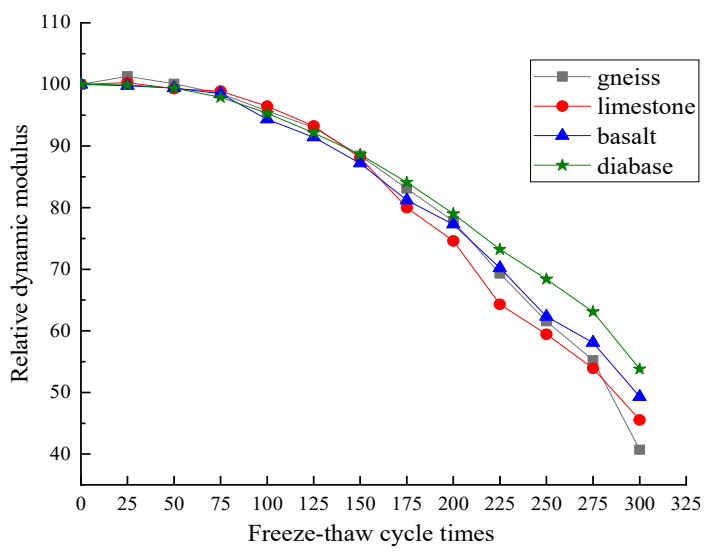

(b) $w / b-0.34$

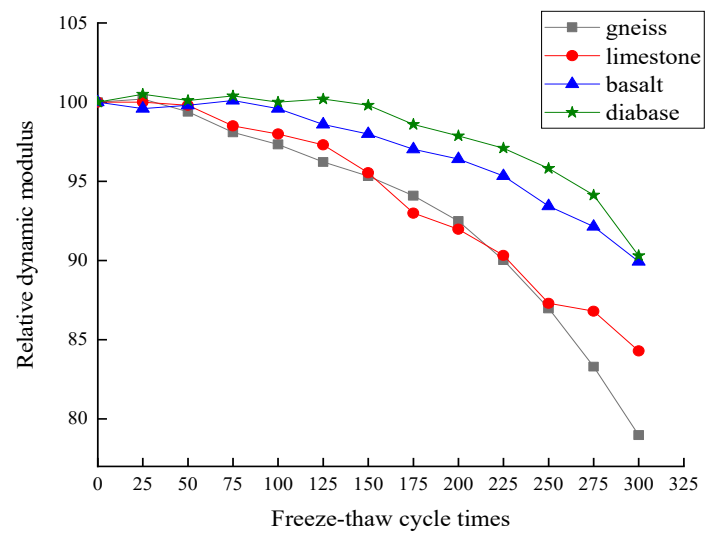

(d) $\mathrm{w} / \mathrm{b}-0.22$

Figure 10. The relative dynamic modulus during freeze-thaw cycles: (a) water-binder ratio of 0.45 ; (b) water-binder ratio of $0.34 ;$ (c) water-binder ratio of 0.30 and (d) water-binder ratio of 0.22 .

\section{Conclusions}

Based on this study, the following conclusions can be drawn.

Due to the influence of water-binder ratio and the water absorption capacity of coarse aggregate, the fluidity of fresh cement concrete can be summarized. The fluidity of fresh concrete demonstrates this order: fresh concrete-gneiss $<$ fresh concrete-limestone $<$ fresh concrete-basalt $<$ fresh concrete-diabase due to the fact that the water absorption capacity of coarse aggregate demonstrates in this order: diabase $>$ basalt $>$ limestone $>$ gneiss, thus resulting in the results of the fluidity. Moreover, the dosage of water-reducing agent increases with the decreasing water-binder ratio due to the fact that cement concrete with lower water-binder ratio possesses less water, thus needing more water-reducing agent.

The mechanical strengths of cement concrete with different types of coarse aggregate depend on the strength and water absorption of coarse aggregate. When the waterbinder ratio is higher than 0.34 , the mechanical strengths are demonstrated in this order: Specimens-limestone $>$ Specimens-gneiss $>$ Specimens-diabase $>$ Specimens-basalt. However, when the water-binder ratio is lower than or equal to 0.3 , the compressive strength decreases in this order: Specimens-diabase $>$ Specimens-basalt $>$ Specimens-limestone $>$ Specimens-gneiss.

The shrinkage rate of concrete firstly keeps an obvious growth trend and then grows slowly with the increasing curing age. The shrinkage rate of concrete with different types of coarse aggregate decreases in this order: Specimens-diabase $>$ Specimens-basalt $>$ Specimens- gneiss $>$ Specimens-limestone. Additionally, the shrinkage rate is increased by reducing the water-binder ratio. 
The chloride ion permeability and freeze-thaw resistance are dominated by the mechanical strengths of the cement concrete with different types of coarse aggregate. The decreasing water-binder ratios lead to the improved resistance to chloride penetration and freeze-thaw cycles. Moreover, the resistance to chloride penetration and freeze-thaw cycles of cement concrete with different types of coarse aggregate increases in this order: Specimens-gneiss $<$ Specimens-limestone $<$ Specimens-basalt $<$ Specimens- diabase. The resistance to freeze-thaw cycles of cement concrete decreased with the increasing waterbinder ratio. Finally, the resistance to freeze-thaw cycles was closely related to the types of coarse aggregate. The influence of coarse aggregate on the resistance to freeze-thaw cycles of the cement concrete depended on the water-binder ratios.

Author Contributions: Conceptualization, L.W. and H.W.; methodology, L.W.; software, H.Y.; validation, L.W.; J.L. and H.W.; formal analysis, C.S.; investigation, C.S.; resources, L.W.; data curation, H.Y.; writing—original draft preparation, L.W.; writing—review and editing, L.W.; visualization, H.W.; supervision, H.W.; project administration, L.W.; funding acquisition, H.W.; All authors have read and agreed to the published version of the manuscript.

Funding: This work is sponsored by the National Natural Science Foundation of China (No. 51878360).

Institutional Review Board Statement: Not applicable.

Informed Consent Statement: Not applicable.

Data Availability Statement: The data used to support the findings of this study are available from the corresponding author upon request.

Conflicts of Interest: The authors declare that there are no conflict of interest regarding the publication of this paper.

\section{References}

1. Mo, Z.; Gao, X.; Su, A. Mechanical performances and microstructures of metakaolin contained UHPC matrix under steam curing conditions. Constr. Build. Mater. 2021, 268, 121112. [CrossRef]

2. Ren, G.; Yao, B.; Huang, H.; Gao, X. Influence of sisal fibers on the mechanical performance of ultra-high performance concretes. Constr. Build. Mater. 2021, 286, 122958. [CrossRef]

3. Choi, H.; Tsujino, M.; Noguchi, T.; Kitagaki, R. Expansion/contraction behavior and cracking control effect of expansive concrete in building structure. Proc. Jpn. Concr. Inst. 2012, 34, 424-429.

4. Ruan, S.; Cise, U. Influence of supplementary cementitious materials on the performance and environmental impacts of reactive magnesia cement concrete. J. Clean. Prod. 2017, 159, 62-73. [CrossRef]

5. He, X.; Zheng, Z.; Ma, M.; Su, Y.; Yang, J.; Tan, H.; Strnadel, B. New treatment technology: The use of wet-milling concrete slurry waste to substitute cement. J. Clean. Prod. 2020, 242, 118347. [CrossRef]

6. Cree, D.; Green, M.; Noumowe, A. Residual strength of concrete containing recycled materials after exposure to fire: A review. Constr. Build. Mater. 2013, 44, 208-223. [CrossRef]

7. Tam, V.; Soomro, M.; Evangelista, A. A review of recycled aggregate in concrete applications (2000-2017). Constr. Build. Mater. 2018, 172, 272-292. [CrossRef]

8. Da, B.; Yu, H.; Ma, H.; Tan, Y.; Mi, R.; Dou, X. Experimental investigation of whole stress-strain curves of coral concrete. Constr. Build. Mater. 2016, 122, 81-89. [CrossRef]

9. Xiao, J.Z.; Li, J.B.; Zhang, C. Mechanical properties of recycled aggregate concrete under uniaxial loading. Cem. Concr. Res. 2005, 35, 1187-1194. [CrossRef]

10. Alexandridou, C.; Angelopoulos, G.N.; Coutelieris, F.A. Mechanical and durability performance of concrete produced with recycled aggregates from Greek construction and demolition waste plants. J. Clean. Prod. 2017, 1, 745-757. [CrossRef]

11. Lye, C.Q.; Dhir, R.K.; Ghataora, G.S. Elastic modulus of concrete made with recycled aggregates Proc. Inst. Civ. Eng. Struct. Build. 2016, 169, 314-339. [CrossRef]

12. Huda, S.B.; Alam, M. Mechanical and freeze-thaw durability properties of recycled aggregate concrete made with recycled coarse aggregate. J. Mater. Civ. Eng. 2015, 27, 04015003. [CrossRef]

13. Li, S.; Jensen, O.; Yu, Q. Mechanism of rate dependent behaviour of ultra-high performance fibre reinforced concrete containing coarse aggregates under flexural loading. Constr. Build. Mater. 2021, 301, 124055. [CrossRef]

14. Liu, C.H.; Fu, J.Y.; Pi, Y.L.; Tuan, C.Y.; Liu, A.R. Influence of demolished concrete blocks on mechanical properties of recycled blend concrete. Constr. Build. Mater. 2017, 136, 329-347. [CrossRef]

15. Nepomuceno, M.; Isidoro, R.; Catarino, J. Mechanical performance evaluation of concrete made with recycled ceramic coarse aggregates from industrial brick waste. Constr. Build. Mater. 2018, 165, 284-294. [CrossRef] 
16. Arumugam, R.; Ramamurthy, K. Study of compressive strength characteristics of coral aggregate concrete. Mag. Concr. Res. 1996, 48, 141-148. [CrossRef]

17. Meyer, C. The greening of the concrete industry. Cem. Concr. Compos. 2009, 31, 601-605. [CrossRef]

18. Qudoos, A.; Kim, H.; Ryou, J.-S. Influence of the surface roughness of crushed natural aggregates on the microhardness of the interfacial transition zone of concrete with mineral admixtures and polymer latex. Constr. Build. Mater. 2018, 168, 946-957. [CrossRef]

19. Beshr, H.; Almusallam, A.; Maslehuddin, M. Effect of coarse aggregate quality on the mechanical properties of high-strength concrete. Constr. Build. Mater. 2003, 17, 97-103. [CrossRef]

20. Szczesniak, M.; Rougelot, T.; Burlion, N.; Shao, J. Compressive strength of cement-based composites: Roles of aggregate diameter and water saturation degree. Cem. Concr. Compos. 2013, 37, 249-258. [CrossRef]

21. Cwirzen, A.; Penttala, V. Aggregate-cement paste transition zone properties affecting the salt-frost damage of high-performance concretes. Cem. Concr. Res. 2005, 35, 671-679. [CrossRef]

22. Bisschop, J.; Van Mier, J. Effect of aggregates on drying shrinkage microcracking in cement-based composites. Mater. Struct. 2002, 35, 453-461. [CrossRef]

23. Bangert, F.; Grasberger, S.; Kuhl, D.; Meschke, G. Environmentally induced deterioration of concrete: Physical motivation and numerical modelling. Eng. Fract. Mech. 2003, 70, 891-910. [CrossRef]

24. Hearn, N. Effect of shrinkage and load-induced cracking on water permeability of concrete. ACI Mater. J. 1999, 96, $234-241$.

25. Lagier, F.; Jourdain, X.; De Sa, C.; Benboudjema, F.; Colliat, J. Numerical strategies for prediction of drying cracks in heterogenous materials: Comparison upon experimental results. Eng. Struct. 2011, 33, 920-931. [CrossRef]

26. Hashin, Z.; Monteiro, P. An inverse method to determine the elastic properties of the interphase between the aggregate and the cement paste. Cem. Concr. Res. 2002, 32, 1291-1300. [CrossRef]

27. Pebble and Crushed Stone for Construction; General Administration of Quality Supervision, Inspection and Quarantine: Beijing, China, 2011; GB/T 14685-2011.

28. Standard for Test Method of Mechanical Properties on Ordinary Concrete; Ministry of Housing and Urban Rural Development of the People's Republic of China: Beijing, China, 2002; GB/T 50081-2002.

29. Standard for Test Method of Long-term Performance and Durability of Ordinary Concrete; Ministry of Housing and Urban Rural Development of the People's Republic of China: Beijing, China, 2009; GB/T 50082-2009.

30. Cho, J.; Joshi, M.; Sun, C. Effect of inclusion size on mechanical properties of polymeric composites with micro and nano particles. Compos. Sci. Technol. 2006, 66, 1941-1952. [CrossRef]

31. Bravo, M.; Brito, D.; Pontes, J.; Evangelista, L. Mechanical performance of concrete made with aggregates from construction and demolition waste recycling plants. J. Clean. Prod. 2015, 99, 59-74. [CrossRef]

32. Miled, K.; Limam, O.; Sab, K. A probabilistic mechanical model for prediction of aggregates' size distribution effect on concrete compressive strength. Phys. A Stat. Mech. Appl. 2012, 391, 3366-3378. [CrossRef]

33. Elices, M.; Rocco, C. Effect of aggregate size on fracture and mechanical properties of a simple concrete. Eng. Fract. Mech. 2008, 75, 3839-3851. [CrossRef]

34. Yurtdas, I.; Burlion, N.; Skoczylas, F. Experimental characterisation of the drying effect on uniaxial mechanical behaviour of mortar. Mater. Struct. 2004, 37, 170-176. [CrossRef]

35. Grassl, P.; Wong, H.; Buenfeld, N. Influence of aggregate size and volume fraction on shrinkage induced micro-cracking of concrete and mortar. Cem. Concr. Res. 2010, 40, 85-93. [CrossRef]

36. Wang, H.; Gao, X.; Liu, J. Eects of salt freeze-thaw cycles and cyclic loading on the piezoresistive properties of carbon nanofibers mortar. Constr. Build. Mater. 2018, 177, 192-201. [CrossRef]

37. Hong, X.; Wang, H.; Shi, F. Influence of $\mathrm{NaCl}$ freeze thaw cycles and cyclic loading on the mechanical performance and permeability of sulphoaluminate cement reactive powder concrete. Coatings 2020, 10, 1227. [CrossRef]

38. Jiang, W.Q.; Shen, X.H.; Xia, J.; Mao, L.X.; Yang, J.; Liu, Q.F. A numerical study on chloride diffusion in freeze-thaw affected concrete. Constr. Build. Mater. 2018, 179, 553-565. [CrossRef]

39. Wang, H.; Gao, X.; Liu, J. Coupling effect of salt freeze-thaw cycles and cyclic loading on performance degradation of carbon nanofiber mortar. Cold Reg. Sci. Technol. 2018, 154, 95-102. [CrossRef]

40. Wang, Y.; Liu, Z.; Fu, K.; Li, Q.; Wang, Y. Experimental studies on the chloride ionpermeability of concrete considering the effect of freeze-thaw damage. Constr. Build. Mater. 2020, 236, 117556. [CrossRef]

41. Sun, L.F.; Jiang, K.; Zhu, X.; Xu, L. An alternating experimental study on the combined effect of freeze-thaw and chloride penetration in concrete. Constr. Build. Mater. 2020, 252, 119025. [CrossRef]

42. Wang, Z.; Zeng, Q.; Wang, L.; Yao, Y.; Li, K. Characterizing blended cement pastes under cyclic freeze-thaw actions by electrical resistivity. Constr. Build. Mater. 2013, 44, 477-486. [CrossRef]

43. Ding, Y.; Huang, Y.; Zhang, Y.; Jalali, S.; Aguiar, J.B. Self-monitoring of freeze-thaw damage using triphasic electric conductive concrete. Constr. Build. Mater. 2015, 101, 440-446. [CrossRef] 